\title{
Sobre el rescate de cautivos y la diplomacia fronteriza en Chile, 1598-1655
}

\author{
Sonia Macarena Sánchez Pérez²
}

Recibido: 9 de enero de 2014 Aprobado: 5 de marzo de 2014

\begin{abstract}
Resumen
Los estudios del cautiverio durante el siglo XVII en la frontera sur de Chile presentan a la fecha un limitado corpus de publicaciones. Dentro de los tópicos más trabajados, destacan los estudios sobre las cautivas, sus imaginarios y aspectos del mestizaje que de él se derivan. Sin embargo, aún no se ha configurado un boceto o tipología de lo que significó el cautiverio en la frontera sur de Chile. Poco se sabe respecto a los aspectos propios de la condición del cautiverio y las dinámicas de captura, rescate o trueques de los prisioneros. Este artículo tiene como objetivo presentar el problema del cautiverio dentro del contexto fronterizo de la primera mitad del siglo XVII, en torno a las relaciones interétnicas hispano-mapuches, y explicar cómo este fenómeno dialogó con el desarrollo de una incipiente diplomacia de carácter mestizo, la que se tradujo en sistemas y políticas de rescate de los prisioneros.
\end{abstract}

Palabras clave: Cautiverio, Cautivos, Frontera, Diplomacia.

\section{On the Rescue of Captives and Border Diplomacy in Chile, 1598-1655}

\begin{abstract}
The studies of captivity during the XVIlth century in the south border of Chile present, to date, a limited corpus of publications. Among the most crafted topics, the studies on the women captives are outlined, their stereotypes and aspects of the crossbreeding that derive from it. Nevertheless, it has not configured a sketch or typology yet on what the captivity meant in the south border of Chile. Little is known about the proper aspects of the condition of captivity and the dynamism of apprehension, rescue or barter of the prisoners.
\end{abstract}

1 Esta publicación es parte de los resultados de la investigación de la tesis doctoral y del proyecto Fondecyt N $N^{\circ} 1100215$ "La diáspora mapuche en Chile colonial. Migraciones forzadas y voluntarias desde la Araucanía hacia el centro y norte de Chile y otras regiones del virreinato peruano (siglos XVI-XVIII)" y recibe apoyo del Centro Interdisciplinario de Estudios Interculturales e Indígenas - ICIIS Instituto de Sociología - Programa de Antropología Pontificia Universidad Católica de Chile (2013).

2 Chilena, Magíster en Estudios Amerindios, Universidad Complutense de Madrid, Doctora (c) en Historia, Pontificia Universidad Católica de Chile. Directora de Estudios, Escuela de Historia, Universidad Finis Terrae. E-mail: msanchez@uft.cl 
This article has an objective to present the problem of captivity within the frontier context of the first half of the XVIIth century, concerning the Hispanic - Mapuche interethnic relations, and to explain how this phenomenon discussed with the development of an incipient diplomacy of mixed birth character, which turned into systems and politics for rescuing the prisoners.

Key words: Captive, Captives, Borders, Diplomacy

\section{Sobe o resgate de cativos e a diplomacia fronteiriça no Chile, 1598-1655}

\section{Resumem}

Os estudos do cativeiro durante o século XVII na fronteira no sul do Chile apresentam à data, um limitado corpus de publicações. Dentro dos tópicos mais trabalhados, destacam os estudos sobre as cativas, seus imaginários e aspectos da mestiçagem que dele se derivam. Porém, ainda não se tem configurado um bosquejo o tipologia do que significou o cativeiro na fronteira sul do Chile. Pouco se conhece ao respeito dos aspectos próprios da condição do cativeiro e as dinâmicas de captura resgate ou troques dos prisioneiros. Este artigo tem como objetivo apresentar o problema do cativeiro dentro do contexto fronteiriço da primeira metade do século XVII, em torno às relações interétnicas hispano-mapuche, e explicar como este fenômeno dialogou com o desenvolvimento de uma incipiente diplomacia de caráter mestiço, que se traduziu em sistemas e políticas de resgate dos prisioneiros.

Palavras chave: Cativeiro, Cativos, Fronteira, Diplomacia.

En Chile la violencia frontal entre españoles y mapuches se desarrolló desde los primeros contactos y presentó dinámicas de ataque diversas. Entradas de guerra de alcances disímiles, con huestes numerosas y otros asaltos de menor alcance, conocidos como malones y malocas, cruzaron gran parte del periodo ${ }^{3}$. Uno de los objetivos más importantes de las malocas, además de la

3 El malón y la maloca era una táctica militar que consistía en un ataque rápido y sorpresivo de un importante número de soldados contra un grupo enemigo, ya fueran parcialidades mapuches enemigas o poblaciones y fortificaciones de españoles o criollos, con el objetivo de obtener ganado, provisiones y prisioneros, sobre todo mujeres y niños. Esta estrategia tuvo su correlato en otros contextos, como el europeo en el sistema de Cabalgata. Este modelo consistía en una ofensiva de carácter estacional de corta duración y que por sus características solía tener una logística mínima, basándose en el autoabastecimiento. La Cabalgata no se veía afectada por las limitaciones forales respecto a la duración del servicio. Era un modelo de lucha de bajo costo, que no requería fuertes inversiones ni grandes avances en materia armamentística. Era sumamente rentable en el corto y mediano plazo, ya que se financiaba con la obtención del botín de guerra, dentro de los cuales los cautivos ocupaban un lugar privilegiado. Además, aseguraba la destrucción de los bienes y tierras enemigos con un mínimo margen de riesgo, lo que a largo plazo debilitaba al adversario 
derrota y debilitamiento del enemigo, era el rescate y/o la captura de piezas, ya sea para su esclavitud o para conseguir, a través del canje, la liberación de otros cautivos. Esta dinámica operó de manera continua a lo largo de todo el periodo y fue una táctica utilizada desde ambos frentes. Mapuches autónomos organizaron asaltos furtivos con el objetivo de liberar a sus parientes, pero también para capturar a otros prisioneros, tanto españoles como mapuches aliados, y usarlos como moneda de canje para rescates. A su vez, las fuerzas españolas y sus aliados mapuches, organizaron sus propias entradas de guerra también para la redención de cautivos y la captura de nuevos prisioneros. Con ellos realizaron importantes negociaciones, ya sea para la paz o para obtener la devolución de otros cautivos. El uso de los cautivos como elementos de negociación, era considerado como parte del proceso de guerra: "en lo que toca a que los indios que cogieren en la guerra no sean esclavos el orden cristiano sino el que los cogiere se pueda servir de ellos y como su majestad ordenare y que pueda rescatarlos como en todas las guerras del mundo se acostumbra y que si de estos fueren menester algunos para enviar con mensajes es cosa justa" (de Valdivia, 1621).

El problema de conseguir rescates desde el punto de vista español, no se circunscribió solo a la redención de cristianos, sino que también era extensivo a la necesidad de rescatar a sus aliados mapuches. Estratégicamente no acudir en rescate de indios amigos representaba un peligro para el futuro de la alianza. Estos pactos interétnicos se fundaban en la asistencia para la guerra, pero también en la protección mutua. Sin embargo, esta motivación muchas veces chocaba con los intereses económicos generados por la venta de los mapuches liberados. El rescate de cautivos indígenas tras las entradas o malocas emprendidas por soldados españoles, no siempre terminaba con el retorno de estos a sus comunidades de origen. Así lo informa el jesuita Gaspar Sobrino, quien expresa "que ninguna destas piecas que se cogieron al enemigo, se entregaron a nuestros amigos sino que parte dellas se dieron algunos oficiales de guerra, y otros se vendieron por ochenta y cien reales de a ocho, conforme a la calidad de cada una dellas" (Sobrino, s/f, a). ${ }^{4}$

y facilitaba la anexión de territorios. Era una forma de guerra que se adaptaba muy bien a las características de una economía agraria que producía pocos excedentes con los que financiar grandes esfuerzos bélicos (Sesma, 2002: 24). Para idéntica actividad realizada por españoles contra indígenas en la época colonial, en cambio, se reserva el término maloca en estos países.

4 Esta práctica de negociación de cautivos tuvo también como antecedente el ejemplo europeo entre moros y cristianos. Las relaciones políticas desarrolladas desde el siglo XIII hasta XV entre Granada y Castilla estuvieron marcadas por cierta indefinición y largos espacios intermedios de paz y guerra. Dentro de estos márgenes, se establecía también un tercer estado, uno que nace de la negociación e impone este término como su expresión cotidiana, el estado de la tregua. Tal situación obligó a constituir códigos comunes y el perfeccionamiento de una diplomacia entre las partes, la que se desplegaba con gran lucidez en tiempos de paz. Las 
Con todo, el trueque de personas pareció ser un mecanismo utilizado entre las partes para conseguir la libertad de sus prisioneros cautivos. Esta práctica condujo a pensar en reservar a ciertos prisioneros en fuertes y presidios en espera de que se concrete el trueque o negociación. Uno de los argumentos que promovía este tipo de práctica era la dificultad que tenían los agentes de liberación para comprar al prisionero mapuche a un particular, como al parecer era lo acostumbrado durante los primeros años de guerra: "para el fin tan deseado del rescate de los españoles cautivos, porque en tiempo de la guerra antigua había dos grandes dificultades para estos rescates" (de Valdivia, 1611). El primero era que cuando se solicitaba algún indio cautivo en trueque de alguna española "era menester que los parientes de la dicha española o el gobernador buscasen ciento o doscientos pesos que pagar al español que poseía al indio esclavo para que lo diece para el rescate"(de Valdivia, 1611). Dada la situación financiera de muchas de las familias afectadas por el cautiverio y la guerra y "como no había orden para gastar en esto la hacienda de VM y había de buscar de limosnas por la pobreza de los parientes de la española, era difícil el rescate". Es por esto que finalmente "venciose esta dificultad con este orden, siendo los prisioneros que se había de trocar libres y puestos en depósito para ese fin, y así se ha rescatado buen número de personas españolas cautivas" (de Valdivia, 1611).

Para mediados del XVII, el intercambio de cautivos parecía ser un sistema común e institucionalizado tanto para españoles y mapuches. Era común que mapuches capturaran y conservaran también a cautivos para usarlos como bienes de intercambio y así rescatar a sus parientes: "que ellos [mapuches autónomos] no tienen mercadería más que españoles y españolas de las que todavía viven de las çiudades perdidas" (Laso de la Vega, 1633). El mismo Laso de la Vega lo expresa en esos términos cuando en 1633 señala que al

treguas cristiano-musulmanas eran instituciones de carácter temporal que instalaban una paz transitoria en el territorio. Estas instancias originadas dentro de un estado de guerra y hostilidades, se presentaron como ideales para la liberación y rescate de cautivos. Las treguas implicaban, por lo general, el pago de tributo de una de las partes, la más debilitada. Si bien la condición de devolución de cautivos en masa era fundamental para determinar el éxito de las treguas -dinámica similar a la vista en los parlamentos hispano-mapuches-, esta medida encontraba sus obstáculos puesto que la población musulmana era reticente a entregar a sus prisioneros. Los cautivos constituían no solo un bien preciado por su valor comercial o laboral, sino un seguro en caso de la captura de algún familiar, característica que -como ya se analizó- se repite en el caso de los cautivos cristianos entre mapuches. Los cautivos cristianos eran una importante "moneda de canje" para realizar un rescate directo. Si los familiares interesados no contaban con un enemigo prisionero, éstos se podían adquirir en el mercado de esclavos o a través de la compra a algún particular que haya participado de alguna empresa bélica, quien tenía la obligación de facilitarles la compra. Por lo tanto, la adquisición de prisioneros en la guerra se presentaba como fundamental para el resguardo de la propia población. Mantener un número importante de cautivos podría representar un seguro a mediano plazo y su entrega constituía un futuro riesgo. 
capturarse a algún indígena se "les exsamina diçiéndoles que si en su tierra su padre madre o hermano o pariente tiene algun español cautibo que [le] dan por él" (Laso de la Vega, 1633).

Los cautivos, por lo general, no eran abandonados a su suerte. Si a través de las armas no lograban conseguir los rescates, se abría paso a la negociación al alero del desarrollo de una incipiente diplomacia que venía estableciéndose en la zona. El éxito o fracaso de una iniciativa militar en parte se medía por la oportunidad que brindaba para conseguir el retorno de un mayor número de prisioneros cautivos. La posibilidad de alcanzar el rescate de cautivos fue parte de las consideraciones del ejército. Al momento de analizar las alternativas de ataque, no se perdía de vista la necesidad de rescate de cautivos. Conseguir dar con el paradero de esposas, hijos o sacerdotes, o líderes militares, y obtener su liberación, influyó en los lineamientos y planificación táctica de los ejércitos.

El acta de acuerdo de la Junta de Guerra celebrada en Santiago de Chile el 18 de junio de 1604, que versaba sobre los recursos para la campaña de Arauco, destacó la necesidad del rescate de españoles cautivos y expresó la preocupación por evitar nuevas capturas de indígenas aliados por parte del enemigo. Entre otros temas señalaba que "para campear, vieren y confirieren si convendrá pasar la guerra a los términos de la Imperial a sacar los cautivos que se pudiesen de los enemigos" o en su lugar estudiar la alternativa de "hacerla en las provincias de Arauco, Catiray y los Angoles, que son los que nos la hacen, inquietando los indios nuestros amigos de los términos de las ciudades de la Concepción, san Bartolomé o ribera de Biobío con intento de levantarlos y llevarlos y a sus mujeres e hijos a sus tierras, como lo han acostumbrado" (García Ramón, 1604).

Los años que abren el siglo XVII constituyeron un periodo de gran complejidad para la ocupación española del territorio y una conquista para la resistencia mapuche. En 1598 se afirmaba el poder mapuche, tras la famosa gesta de Curalaba, que dio como resultado la pérdida de todas las recién fundadas ciudades españolas en el sur. ${ }^{5}$ Una de las consecuencias más do-

5 Entre 1598 y 1604 se produjo el gran alzamiento que llevó a la pérdida total de los asentamientos del sur. Este hecho es considerado como uno de los traspiés militares más importantes para las fuerzas españolas en el Nuevo Mundo. Las ciudades, especialmente Valdivia y Osorno, se habían perfilado durante los años previos como urbes relevantes y eran consideradas potenciales centros neurálgicos de la ocupación. Valdivia constituía una ciudad amurallada, con más de 600 españoles y numerosos indios tributarios, hasta que las fuerzas de Anganamón, Paillamachu y Pelantaru asolaron el lugar. La ciudad fue abandonada hasta 1643. Se contaba en más de 300 las mujeres cautivas, llegando algunos testigos a afirmar que eran más de 500. Entre ellas estaban monjas de conventos y mujeres de importancia, como es el caso de Esmeralda, hija del capitán Valenzuela, que fue rescatada varias décadas 
lorosas de este enfrentamiento fue la captura de un número importantísimo de cautivos. En este escenario, la preocupación por el rescate se reiteraba en la mayor parte de los informes de guerra, dando cuenta de los esfuerzos por revertir la situación. En la sociedad colonial se instaló con gran fuerza el imaginario del cautiverio, especialmente en los asentamientos contiguos a las fronteras.

En 1604, mismo año en que se publicaba el acta de la junta de guerra antes citada, que ponía de manifiesto la necesidad por la redención de los cautivos, el gobernador García Ramón, comenzaba una campaña militar en la zona, con una lógica similar. En noviembre llegaron a Santiago 952 soldados, de un total de mil que Felipe III había enviado al territorio. Era el mayor contingente conseguido gracias a las gestiones del gobernador, a lo que se sumó el auxilio del Real Situado asignado a Chile para el pago y manutención de las tropas. El plan era realizar una entrada a través de diferentes flancos a tierra de guerra, someter al enemigo y conseguir el rescate de cerca de doscientos cautivos, entre los que se contaban hombres, mujeres y niños tanto españoles como mapuches aliados tomados prisioneros durante los últimos seis años. Sin embargo, a pesar de los esfuerzos desplegados en sus campañas, luego de siete meses de incursiones, se reconocía el día 15 de agosto de 1606, que solo habían "rescatado y liberado de su poder a fuerza de armas quince españoles y entre ellas ocho mujeres" (García Ramón, s/f), aunque otro informe firmado por Lorenzo del Salto, que se refiere a los rescates alcanzados ese mismo año por las campañas del gobernador menciona unas cuantas más (Del Salto, 1606). Con todo, era un número muy modesto en relación con la cifra estimada al inicio de la operación.

García Ramón informaba detalladamente el proceso del rescate ejecutado, apuntando su esperanza en el poder bélico de sus tropas y en el polémico sistema de guerra ofensiva para someter a los mapuches rebeldes y lograr la libertad de los cautivos. ${ }^{6}$ Si bien el número de personas redimidas no era de importancia, su estatus sí lo era. En el informe de Lorenzo del Salto respecto de los rescates del gobernador y su ejército, se destacaba la presencia de

después, para terminar recluida en un convento. Entre los muertos, se encontraban los capitanes Gómez Romero y Alonso Pérez de Valenzuela y Buiza, y más de cuatrocientos adultos y cincuenta niños españoles. Rosales y otros testigos dan cuenta del episodio con profundo sentir. Para profundizar este tema es posible consultar Guarda (1990 y 1993) y Urbina (2009).

6 Así lo expresó adelantando que no obstante los resultados, confiaba "en la misericordia de Dios que dentro de poco tiempo, aunque es grande el número de mujeres que tienen cautivas se han de ver libres de los grandes trabajos y miserias que padecen". Solo pedía que él y su ejército pudieran mantener la ayuda del Estado y contar "con lo principal que es lo que es suplicado a Vuestra Magestad mande proveer no hay duda sino que la guerra de este Reino ha de tener muy gran mejora de todo" (García Ramón, 1606a). 
una veintena de mujeres con el apelativo de "doñas". ${ }^{7}$ Entre ellas se contaba el nombre de doña Inés de Castañeda, española, prisionera en la toma del fuerte de Boroa y rescatada en 1606 por el capitán Francisco Gil Negrete en La Imperial, con un hijo de poco más de un año. El niño, mestizo, según registra Medina (1906: 191), habría tomado el hábito de Agustino en 1621. También figuraba en la nómina Leonardo Cortés, quién ostentó títulos como los de corregidor y procurador general del ejército. Su hija se habría casado más tarde con el capitán Andrés de Escobar (Medina, 1906: 217).

La pérdida territorial de la zona sur y la captura de miembros de la sociedad criolla, había generado entre la población hispana una sensación de indefensión; un espíritu de derrota y desolación que se manifestó durante largo tiempo. Hombres, mujeres y niños que formaban una emergente elite local fueron parte de este desolador número de prisioneros. En aquella ocasión, las pérdidas no se reducían a un grupo de soldados o algún misionero internado en zonas riesgosas. En este caso, los muertos y cautivos eran mayoritariamente civiles y, por esta misma razón, su rescate cobró más importancia que nunca. Durante los primeros años se consiguió la liberación de cautivos españoles y mapuches aliados gracias a entradas de guerra, canje, compra y negociaciones bilaterales. Otros cautivos tuvieron que esperar aún más tiempo para su liberación, como Marco Chavarri de Almonacid, quien se declara "hijo y nieto de los primeros conquistadores de este reino" y vecino de Villarica, quien permaneció más de veinticinco años como prisionero, tras ser capturado durante estos años en las cercanías de Angol (Medina, 1906: 232).

7 Según el informe de Lorenzo del Salto respecto a los rescates del gobernador, se avisa que: "Memoria de las personas que se han rescatado de poder del enemigo en la guerra de Chile a siete meses a esta parte que entró a campear el señor Alonso García Ramón governador del dicho Reyno: El capitán Pablo Hernández de Córdova, Doña Ynes Veas, Jusephe Hernandez, Doña Luçia de la Puente, Mateo de Chaves Tablada, Doña Marcela de Sauçedo, Diego de Godoy, Doña Veatriz de Navarrete, Don Juan de Maluenda, María Pardo, Leonardo Cortes, Doña Ynes de Castañeda, Pedro Portillo, Doña Mariana de Ayala, Juan Chavero, Doña Anna de Paz, Alonso de Torres, Doña Ysabel de Villarroel, Diego Ramón, Doña María de Cerveros, Alonso, niño de poca edad, Doña Ana Díaz Tellez, Diego Gordillo, Veatriz de los Reyes, Diego Bacan, Doña Veatriz de lo Caña, Pedro de Sauçedo, Francisca Hernandez, Diego de Figueroa, Francisca García, El capitán Juan de León, Doña Baltasara de León, Gaspar de Ocampo, Doña Clara de Larrea, otro hermano suyo Doña María çapata, Vernardino de Bungos, Doña María de la Puente, Valtasar Cabrito, Doña Petronila Varua, Jacome Pérez, Doña Úrsula de Alvarado, Juan de la Parta, Doña Ysabel Muñoz de Ávila, Mariana, niña de poca edad, Doña Marcela de Fugueroa, Doña Leonor de Chaves Tablada, Ynes Ramírez, Juana Gonçalez, Ynes Minel, Anna Velázquez Rengel, Francisca Monje. Un mulato llamado Diego Hernández, un negro llamado Andrés, barrerain, yndios e yndias cristianos que se an rescatado. Las quales dichas personas, avia la que menos siete $u$ ocho años questaba cautiva, entre los enemigos hasta oy 15 de agosto de 1606 años y se an rescatado en mi presencia a lançadas y trocadose algunas por prisioneros y algunos géneros de ropa y dello doy fee. Lorenzo del Salto [Firmado]" (del Salto y García Ramón, 1606). 
Cerca de un tercio de la población quedó en cautiverio. El impacto humano que se verificó tras el levantamiento que terminó con las ciudades ubicadas al sur del río Bío-Bío, se puede apreciar en dos planos. El primero de ellos es el material, que provocó un brusco retroceso en la economía, a partir de la pérdida de pertrechos, armas y población. El segundo impacto "fue más bien psicológico y se manifestó nítidamente en una sensación generalizada de inseguridad y desmoralización por parte de la sociedad hispana, ahora agudizada por una nueva preocupación: la pérdida masiva de seres queridos que terminaron en condición de cautivos entre los mapuches" (González, 2001-2002: 73). El desconsuelo y preocupación tras evidenciarse los primeros reveses en los rescates protagonizados por el ejército español, sirvió como argumento para desacreditar el método de guerra ofensiva e instalar la necesidad de una estrategia diferente, el de la guerra defensiva. En 1608, el Padre Gaspar Sobrino, miembro de la Compañía de Jesús, a quien el Padre Luis de Valdivia había enviado a Chile, explicaba en una carta al rey, algunas razones que probaban la eficacia del modelo defensivo para conseguir liberar a un mayor número de cautivos cristianos retenidos por las fuerzas mapuches. ${ }^{8}$ Según el religioso, el segundo beneficio que percibe en este cambio de estrategia fue "facilitar con este nuevo modo de guerra [defensiva] el rescate de las cautivas, que ya no son quinientas como el Maestre de Campo Pedro Cortés dize en un Memorial que presentó a V.M." (Sobrino, s/f, b).

En un periodo muy corto de tiempo se habrían conseguido, gracias a las conversaciones de paz, el rescate de un porcentaje considerable de personas, muchas de ellas vecinos de importancia en la región, individualizados con su nombre y título de "don". En palabras del jesuita: "y de los efectos deste motivo ya hemos gozado, pues en poco mas de un año se han rescatado don Alonso de Quesada, el Sargento Juan de Torres, Francisco Fernandez, un P. Dominico y tres mugeres, que por todos son siete". Finalmente destaca "y esto cierto es, que no se puede atribuir a la guerra ofensiva, pues no la avia, ni jamás con ella en quatro años se han rescatado tantos, y con la defensiva y la experiencia nos enseña que sí (...)" (Sobrino, s/f, b).

8 Luis de Valdivia (1561 -1642) fue un jesuita español que arribó a Chile en 1593 junto a otros miembros de su Orden, dedicándose a la evangelización y visitando los pueblos del sur del territorio. Tras la derrota española en Curalaba, la muerte del gobernador y la legalización de la esclavitud mapuche, su acción se concentró en la defensa y planteamiento de la guerra defensiva, sistema que se aplicó entre 1612 y 1625 . Se había instalado la idea que el medio más eficaz para concluir con la Guerra de Arauco era la supresión del servicio personal de los indígenas y el término de la guerra ofensiva, lo que debía ir acompañado por un esfuerzo de conversión al cristianismo. En esta línea el nuevo gobernador Alonso de Ribera crea una nueva estrategia consistente en fortificar el río Bío-Bío y mantener guarniciones de soldados permanentes en la zona. Estos fuertes debían ir lentamente avanzando sobre el territorio mapuche consolidando la conquista. 
Efectivamente, como lo señalaba el padre Sobrino muchas de las entradas de guerra no daban los resultados esperados e incluso podían ocasionar más pérdidas que rescates, como fue el caso de la campaña del gobernador García de Ramón en 1606. Bajo este escenario, otras opciones como el canje o trueque cobraron fuerza como mecanismos alternativos de liberación frente a la opción del ataque frontal o entrada de guerra. Estos métodos de rescate que tenían como procedimiento el diálogo y la negociación, claramente requerían del soporte de un lenguaje común, del avance de una diplomacia mestiza.

Si bien uno de los principales patrimonios usados para el canje de un cautivo era, de hecho, otro cautivo, capturado generalmente gracias a una incursión violenta, el proceso de canje se desarrollaba dentro de un formato de acuerdo entre las partes. En 1611 se solicitaba que los mapuches "que de allí adelante se confiesen en la guerra defensiva no fuesen esclavos, sino que los muy culpados se castigasen y los demás se depositasen, para que por ello se rescatasen algunas personas españolas, de las que antiguamente cautivaron en las ciudades que se llevaron" (Archivo del Arzobispado de Santiago, 1611). Este proceso de intercambio de cautivos fue fortaleciendo el manejo de una suerte de protocolo interétnico, cuyo modelo se fue instalando a lo largo de estos años.

El proceso de canje contemplaba una serie de pasos protocolares, los que se fueron perfeccionando y modificando de acuerdo a las circunstancias y el desarrollo de las relaciones bilaterales. Una vez iniciadas las conversaciones y negociaciones, había que determinar por cuántos cautivos o por cuáles de ellos, específicamente, se ofrecería la libertad de un prisionero. Una vez acordado este punto, los agentes mediadores o quienes lideraban el proceso de intercambio, necesitaban ubicar a los amos de los cautivos que servirían para el trueque o canje y negociar con ellos un pago o compensación justa para conseguir que los entreguen: "el enemigo enbia luego a saver donde paran las dichas piessas de yndios e yndias para tratar de rescate" (Laso de la Vega, 1633). Esto, en el caso que los cautivos no se encontraran ya reservados para estos fines desde su captura, lo que de ser así, era probable que se encontraran prisioneros en los mismos fuertes o en poder de las autoridades a la espera de que se concrete su entrega por otro prisionero. ${ }^{9}$ Por lo general,

9 Respecto a esta costumbre de "reservar" desde el inicio ciertos cautivos para su canje, existen importantes referentes en el contexto europeo. Informa Emilio Cabrera, en el contexto mediterráneo, que los cautivos estaban claramente diferenciados respecto a su estatus y finalidad. Existían dentro de ellos los conocidos como cautivos de rescate, cuyo destino principal era ser entregado ya sea por otro cautivo o por una compensación económica. Estos cautivos no realizaban labores o tareas muy pesadas o riesgosas sino que se mantenían recluidos en espera de su liberación (Cabrera, 1996). En el caso chileno, existen indicios de que, en ciertos casos, la dinámica pudo ser similar, en la medida de que si se establecía el carácter "canjeable" de un prisionero, ya sea español o mapuche, a estos se les sometía a 
una vez ubicados a los amos, "les dé a los padres algunas cosas para que den a los caciques y a los indios para ganarlos" (Reino de Chile y Colegio de Santiago, 1577-1613). En el caso español, los mediadores debían contar con una autorización especial para comenzar las gestiones. Finalmente, la transacción con la contraparte eventualmente podía apoyarse con la entrega de otros bienes, dentro de los cuales era común encontrar paños, chaquiras, animales, entre otros.

En 1612 el sargento Pedro Melendes, que acompañó a Luis de Valdivia, por órdenes de Alonso de Rivera, para tratar la paz con los sectores mapuches en guerra, daba cuenta en primer lugar de la delicadeza de la diplomacia, la complejidad del desarrollo de las relaciones interétnicas y la importancia de contar con prisioneros de relevancia así como también de agentes mediadores al momento de negociar una liberación de cautivos: "en cumplimiento de lo que centró en las provincias de guerra de los dichos enemigos de Purén i Payllaguen, Imperial, Boroa i Maquegua i otra provincia en que pasó notorio peligro de su vida acudiendo a lo que llevaba a cargo donde no saliera de perpetuo cautiverio si no fuera por un indio llamado Turelipe, grandemente estimado de los indios de guerra, que estaba prisionero en el castillo de Arau$\mathrm{CO}$, a cuyo rescate i de otras piezas de los enemigos trujeron a este declarante i alférez don Alonso Pérez de Quezada i al alférez Juan de Torres cautivos que tenía el enemigo a Paicaví" (Archivo Arzobispado de Santiago, 1613).

Bajo el modelo canje se consiguió la liberación de un importante número de prisioneros. A menos de siete meses de iniciadas las gestiones del gobernador Francisco Laso de la Vega (1633) notificó que "rescaté una muger prinçipal que a 33 años que estava cautiba y en tiempo de un año he sacado 22 españoles de cautiberio y muchos yndios de los amigos que estavan así mesmo cautibos fuera de muchos que se me han venido como hago relaçion en la que enbio a Vuestra Magestad de los subcessos de la guerra". El objetivo del documento era destacar que bajo este procedimiento de negociaciones y parlas, que promovía el rescate a través del canje, el número de cristianos redimidos era superior al ofrecido por la guerra a sangre y fuego o guerra ofensiva. Es por esto que no resulta extraño que la práctica de capturar piezas con el objetivo de utilizarlas como moneda de trueque para el rescate de prisioneros se haya institucionalizado. La documentación así lo manifiesta en reiteradas ocasiones. Los informes o cartas sobre el estado de la guerra en Chile, hacen referencias una y otra vez a este modelo de rescate. Dentro de este mismo sistema fue rescatado Nuñez de Pineda, el jefe mapuche Turalipe y el sacerdote Juan Falcón, entre muchos otros. Así lo declaró este último,

un trato diferente. En el caso de los cautivos mapuches, estos quedaban por lo general en los fuertes como prisioneros y no eran desterrados o esclavizados. 
cuando se le preguntó cómo salió de poder del enemigo, "si le dejaron venir libremente o si fue rescatado o trocado por algún prisionero y quién le regato y en que tiempo" respondiendo que hace tres meses más o menos Alonso de Rivera "dio en rescate a los enemigos un cacique principal de ellos llamado Lincalebo que estaba preso en el fuerte de el Nacimiento" y que para este efecto sus "parientes y deudos le compraron del dicho Guenucuca su amo de adonde se vino a esta dicha ciudad que habrá ochenta leguas poco más o menos a su convento y religión a cumplir con su obligación y lo que tiene profesado" (Falcón, 1614).

A través de este documento se observa parte importante del desarrollo del sistema de rescate a partir del truque. Gracias a la captura de un cacique de relevancia como lo era Lincalebo, los mapuches comenzaron un proceso de negociación con las fuerzas hispanas para conseguir su rescate. El cacique, como solía ocurrir con otros prisioneros de importancia, era recluido en el fuerte, a diferencia de otros cautivos mapuches que usualmente eran vendidos como esclavos y desterrados. Los agentes mediadores acordaron como parte del intercambio o "moneda de canje", la entrega del sacerdote. Como Falcón no se encontraba en poder de los interesados en este caso, los parientes y miembros del Rewe de Lincalebo se vieron obligados a comprar la libertad del prisionero con su amo Guenucuca y así poder concretar la entrega.

En algunos casos, cuando no se contaba con otro prisionero para intercambiar o simplemente porque el rescate no estaba dentro de las prioridades de quien poseía a un cautivo, la transacción podía ser fijada en dinero o más comúnmente especies. La libertad del cautivo entontes era "comprada" a su amo. El desarrollo de un temprano comercio fronterizo permitió identificar y equiparar productos de interés para intercambio en estas instancias. La mayor parte de los acuerdos que implicaba el pago por la liberación de un cautivo comprometieron la entrega de bienes de alta demanda en el mercado desarrollado entre hispanos y mapuches. En 1606 el licenciado Juan de la Fuente, Vicario General, el padre fray Juan de Lagunilla de la orden San Francisco y el padre fray Juan de la Barrera con dos compañeros sacerdotes de Nuestra Señora de la Merced acompañaron al gobernador para la ayuda en las labores de rescate. El predicador que "juntamente traía oficio de redentor de cautivos para lo cual traía el dicho padre fray Juan de la Barrera cinco mil patacones en ropas y sedas que su religión pidió de limosna en la ciudad de los Reyes en compañía del dicho gobernador para rescatar las señoras cautivas" (García Ramón, 1606c). El cautivo pasó a constituir una mercancía transable en el contexto fronterizo. Se pagaba por su rescate, así como también servía de pago por otro rescate.

Llama la atención la condición de la comitiva que acompañaba al gobernador en las labores de rescate. Un vicario general, el padre Juan de 
Lagunilla y la trayectoria de quien oficiaría como redentor, el fray Juan de la Barrera. Según registra Medina, se trataba de un religioso letrado y con una importante carrera en la Orden de la Merced. Hijo de Gaspar de la Barrera y Luciana de Vergara y hermano del militar Pedro de la Barrera, quien entre otras cosas se desempeñó como maestre de campo y gobernador de Chiloé en 1612. Juan fue maestro durante muchos años en Convento de la ciudad de los Reyes, lector de teología y uno de los predicadores de importancia. En Chile, fue comendador y vicario provincial y el primer maestro de teología graduado en la Universidad de Lima (Medina, 1906: 116-118).

Su rol en la frontera y especialmente como mediador parece ser reconocida por las autoridades. Según explica Medina, se distinguió en los encuentros que mediaron con los indios durante el sitio de La Imperial, y especialmente en el año 1606, en que "con los hábitos en cinta, fue dando a todos municiones y animando a los soldados". Su madre en el memorial que se presentó al Consejo de Indias de 1616, decía: "Ha servido a Vuestra Magestad con su persona, llevándole consigo el gobernador Alonso García Ramón en el y [sic] ejército real cuando fue a poblar la Imperial y a sacar de cautiverio las mujeres españolas para que el dicho fray Juan, su hijo, tratase con los indios rebelados su rescate, como lo hizo con su buena industria, rescatando más de cuarenta y predicó a los españoles e indios el Santo Evangelio, con gran aceptación y provecho de las almas" (Medina, 1906: 232). También habría prestado un servicio similar como mediador y evangelizador entre soldados e indios de paz y de guerra con los gobernadores Luis Merlo de la Fuente, Juan Jara Quemada y Alonso Ribera (Medina, 1906: 232).

Para este mercedario, cuya historia estuvo cruzada por la guerra y las relaciones fronterizas, los conflictos en tierra de guerra no eran tema nuevo, especialmente el cautiverio. Su hermano Francisco, también militar de rango, estuvo cautivo durante más de tres años "pasando excesivos trabajos y mala vida". Según se desprende de lo señalado por Medina, habría sido capturado en Cuyuncaví en 1609, durante la última campaña de García Ramón en las provincias del sur entre 1609 y 1610. Ese año el maestre de Campo Diego Bravo Saravia lideró varias correrías en el sector de Tucapel con alrededor de 350 soldados. Menospreciando la capacidad bélica del enemigo, marchó e inició una seguidilla de ataques sin encontrar una mayor resistencia en sus inicios. Sin embargo, a mediados de diciembre en Cuyuncaví fue emboscado por guerreros de Purén, donde no pudo imponer mayor resistencia. Treinta y cuatro españoles murieron o fueron capturados, entre los que se contaría el hermano del mercedario. Así y después "setenta y tres ventas sucesivas" que declara Medina, estuvo ubicable para su familia. En 1612 su hermano Pedro iniciaría una campaña en la zona cuyo objetivo era su rescate, el que consiguió por un costo de más de cuatro mil ducados (Medina, 1906: 118). 
Sin embargo, no todos los canjes terminaban en éxito, entre otras razones porque no todos los prisioneros eran igualmente estimados. No siempre estos intercambios de cautivos los protagonizaron y gestionaron los familiares o cercanos al sujeto en cautiverio y, en algunas ocasiones, como cuenta Ovalle el caso de una anciana española, "la cual trajeron dos mancebos [indígenas] en rescate de su padre... y el Maestre de Campo no se contentó del trueque por ser ya vieja esta cautiva y así, depositándola allí, volvieron por otra" (Ovalle, 1696, citado en Guarda, 1987: 120). Otra dificultad que podía ofrecer el sistema de trueque o canje, lo constituyó el mismo Estado o el poder eclesiástico, quienes a pesar de considerarlo una labor piadosa y necesaria, veían en él un peligro estratégico, dada la información que podían proporcionar los retornados, o un mecanismo que dejaba importantes pérdidas de almas en proceso de conversión.

Los cautivos mapuches, una vez en poder español, eran por lo general bautizados, por lo tanto, retornarlos en una etapa temprana no hacía más que asegurar su apostasía. Ya en 1611 se expresaba esta aprensión y se establecía como una de las dificultades para conseguir la liberación a través del sistema de canje de prisioneros. Es por ello que se precisa que "como todos los indios antiguamente cogidos en la guerra eran ya cristianos, no se podían enviar a tierra de infieles en trueques, conforme a buena conciencia". De este modo se ordenaba que solo los indios infieles que se cogiesen de aquí en adelante, de quienes se esperare rescate, que no quisiesen ser cristianos se guardasen para estos trueques (Memorial del padre Luis de Valdivia de la Compañía de Jesús sobre hacer la guerra defensiva a los indios, Archivo Arzobispado de Santiago, 1611). Esta interpretación es reiterada ocho años después en un documento que establece que se debe llevar a discusión el asunto del canje de cautivos, pues si bien es deber salvar las almas de tantas mujeres españolas cautivas, el trueque que tenía como objetivo "el útil rescate de los nuestros sacándolos de entre infieles donde corren tanto riesgo sus conciencias con que no multiplicaran su generación en las españolas que tienen en su poder"; sin embargo, en el párrafo siguiente declara que debe quedar claro al mismo tiempo que era un riesgo que los indios canjeados y ya bautizados "se degenerasen a apostatar entre los demás" (Biblioteca Nacional, 17 de mayo de 1619).

A lo anterior se suma el hecho de que en ciertas ocasiones se hacía imposible concretar los rescates principalmente por el largo tiempo transcurrido para conseguir autorización para efectuarlos y la obtención de fondos para llevarlos a cabo. En este plazo muchos cautivos eran trasladados a otras zonas, ya por venta y esclavización o por la movilidad del captor. Con todo, estas acciones más o menos particulares de negociación en torno al rescate fueron desarrollando un entramado de acomodos y vínculos interétnicos que se afirmó en el progreso que tuvieron las relaciones fronterizas en la zona, 
llegando incluso a constituir el rescate una parte de una institucionalidad colectiva de negociaciones bilaterales, como lo fueron los parlamentos (Zavala, 1998: 185-208).

Con todo, ambos sistemas de rescate, aquel resuelto desde la negociación interétnica así como el alcanzado en las entradas de guerra, se dieron cita durante todo el periodo. Pese a los detractores o defensores de cada modelo, muchos utilizaron ambos sistemas con el fin de recuperar a sus prisioneros. Ignacio Carrera Iturgoyen, gobernador de Chiloé para mediados de siglo, logró la liberación de cautivos, entre ellos el jesuita Agustín de Villaza, capturado mientras dictaba misa, además de la paz de los sectores rebeldes, todo gracias al uso de las armas. Carrera Iturgoyen mantuvo su protagonismo en los asuntos de guerra, gracias a su experiencia en estos años resistiendo y atacando parcialidades indígenas. En el conflicto de 1655 ostentaba el cargo de sargento mayor del reino, cabo del tercio de Santa María y fronteras del Bío-Bío (Medina, 1906: 174-175). Así, el rescate por las armas pareció retomar su protagonismo a la luz del conflicto que medió el siglo. La biografía del capitán Alonso de Córdova y Figueroa exhibe en su semblanza el rescate de "ciento ochenta personas de ambos sexos", una vez construido el Fuerte de Tolpán en 1657, por la orden del gobernador de Pedro Porter Casanate, en el entonces territorio mapuche. El capitán de Córdova y Figueroa utilizó esta fortaleza para emprender contra los mapuches, durante la insurrección mapuche de 1655 (Medina, 1906: 211).

El canje entre prisioneros exigía establecer ponderaciones, tales como el estatus del sujeto a intercambiar y el interés de la contraparte por conseguir su rescate. No todos los cautivos eran igualmente importantes desde el punto de vista de quienes estaban a cargo de la negociación y, por lo tanto, no siempre la reciprocidad se establecía de "uno es a uno" o el paso de un cautivo por otro. Dependiendo de la relevancia social y/o militar del prisionero, su liberación podía costar la entrega de más de un individuo y sumarse además el pago en especies. Los intercambios podían gestionarse para el rescate de un solo cautivo o un grupo de estos y las negociaciones comprometían a una amplia red de personas para lograrlo. No se trataba solo de una empresa que organizaba la familia directa de los cautivos, aunque en primera instancia fueran estos quienes impulsaran el proceso. Dado el contexto, se hacía necesaria la intervención de agentes mediadores que concretaran la transacción. ${ }^{10}$ Entre estos personajes de mediación destaca el

10 Estos agentes mediadores podían ser soldados o sacerdotes, principalmente jesuitas y mercedarios, así como también otras autoridades locales e incluso comerciantes. Todos ellos tenían en común ser individuos que transitaban entre los dos mundos y que contaban con una red de contactos que los instalaba como interlocutores válidos para españoles y mapuches. 
rol de autoridades mapuches y españolas, tanto civiles, religiosas y militares. En el caso de las autoridades civiles, el rescate se presentó como un objetivo de relevancia para españoles y mapuches. Fue parte de la labor militar y misional en la frontera. El Maestre de Campo Diego Bravo de Saravia declaró haber capturado " 24 yndios los más de ellos caciques principales y capitanes y se mataron 12 de donde resultaron sucesos muy deseados. El primero fue comenzarse el rescate de cautivos a trueque de los dichos yndios prisioneros". Gracias a tal empresa en un plazo de diez días habría logrado la liberación de "22 personas españolas las más de ellas de mucha calidad y dozena y media de yndios e yndias cautivas" (García Ramón, 30 de diciembre de 1605). ${ }^{11}$

En el documento citado, queda en evidencia la importancia de la captura con el fin de liberar a prisioneros y cómo se establecía y discriminaba según el estatus concedido a un prisionero, en este caso, "caciques muy principales". Por lo general, los cautivos que gozaban de mayor reputación no eran vendidos ni desterrados, sino reservados para el canje o asesinados por represalia y como una manera de venganza simbólica ante el poder enemigo. Los prisioneros podían ser valorados según su género, oficio o red social y esto determinaba en gran medida su destino, ya sea la venta, esclavitud, intercambio o asimilación del cautivo al interior de la comunidad. Desconocemos si existía alguna predilección o valor particular desde el punto de vista del género a la hora de establecer qué cautivos serían reservados o considerados más idóneos para el canje, o si sólo dependía del interés de las partes. ${ }^{12}$ Lo que sí parece claro era que tanto mujeres como niños fueron integrados con mayor facilidad al interior del grupo captor. Así lo declaró Diego de Medina (12 de abril de 1615), cautivo que una vez liberado fue consultado respecto a la cantidad de cautivos españoles que existía en el periodo, señalando que "cautivas hay en poder del enemigo más de doscientas y que todas las más de ellas tienen hijos de los indios y que españoles hay pocos porque los han muerto en borracheras y otras ocasiones". Así también lo especifica otro documento destinado a analizar el rescate de cautivas y cautivos españoles en tierra de guerra. En él se explica la necesidad de "confesarlos y consolarlos que según buena doctrina estando como estaban tantos años entre infieles

11 Diego Bravo de Saravia fue nombrado Maestre de Campo por el gobernador Alonso García de Ramón en julio de ese mismo año 1605. Tras su participación en la guerra, al parecer de manera destacada, continuó una carrera militar ascendente. En 1611 el marqués de Montesclaros lo nombró Almirante de la armada que llevaba a Panamá los tributos del Perú (Medina, 1906: 139-140).

12 Emilio Cabrera explica, respecto a los rescates de cautivos en Granada, que llama la atención la enorme disparidad entre hombres y mujeres, representando los primeros cerca del $87 \%$ de los registros de liberación. Esto se explica, entre otras cosas, porque la liberación de mujeres era más problemática debido al gran interés por hacer de ellas, esclavas o concubinas. Muchas pasaron a integrar las familias de sus captores, tuvieron descendencia y apostaron en el proceso, por lo tanto, su recuperación se hacía casi inviable (Cabrera, 1996: 114). 
y bárbaros, bien ha hecho de ver que tenían extrema necesidad espiritual de ser ayudados y (...) lo más que están en cautiverio son mujeres" (Reino de Chile y Colegio de Santiago, 1577-1613). Algunas mujeres españolas o mapuches cautivas, llegaban a ser concubinas o esposas de caciques autónomos. Los niños tomados en la guerra también eran criados como hijos. ${ }^{13}$ Algunas mujeres mapuches cautivas entre españoles también se dedicaron al servicio doméstico o pasaron a ser concubinas de sus captores. En todos estos casos pudo ser más compleja su entrega como pago o intercambio por otro prisionero. Esta dificultad pareció estar presente para las autoridades y agentes de mediación. Es por ello que se advierte que "los padres vayan haciendo memoria de los cautivos y quien sean sus amos y cuanto piden por su rescate y que no tasen de las que están casadas con indios por ahora" (Reino de Chile y Colegio de Santiago, 1577-1613b).

Los cautivos que fueron asimilados de una u otra forma al grupo familiar extendido, desempeñaron un rol económico importante como fuerza laboral. Las cautivas mapuches se dedicaron al servicio doméstico y cautivas españolas fueron parte de la fuerza de trabajo del grupo familiar. ${ }^{14}$ Los hombres, en general, cooperaban en todo tipo de labores productivas. Asimismo los españoles, mestizos o indios amigos cautivos o fugados muchas veces eran conservados con vida aprovechando sus conocimientos en el manejo de las armas, estrategia y elaboración de la pólvora. Este fue el caso de Gregorio de Hinestroza, cautivo desde 1609 hasta 1621, quien, según Rosales, habría sido muy bien tratado gracias a su astucia: se presentó como herrero. Desempeñó así esta labor muy valorada entre mapuches y lo que significó que lo trasladaran a distintos sectores para ejercer su oficio y le ofrecieran obsequios y mujeres. En 1621 Hinestroza vuelve con otros cautivos a Negrete. Es difícil saberlo, pero si confiamos en la mirada de Rosales, quien señala que dichas ofrendas eran para conseguir "perpetuarle consigo", cabría pensar que el soldado gozaba de cierta libertad y autonomía y que su "fuga" o mejor dicho retorno lo concretó cuando él estimó conveniente. ${ }^{15}$

13 Si bien no existen estudios que profundicen en este tema, la documentación indica que de ambos sectores existió un número muy significativo de niños cautivos. Según Fernando Operé (2001: 112-113), dentro de la documentación emanada de la liberación de cautivos españoles en la frontera trasandina durante principios de siglo XIX, se puede constatar que de los 245 hombres rescatados de cerca de 700 cautivos, la edad promedio al momento de su rescate era de 13 años. Cerca del $62 \%$ de ellos no podían recordar su captura. Susan Socolow (1992: 79-81) reafirma estas conclusiones señalando que la mayor parte de los cautivos hombres eran niños menores de 13 años.

14 Numerosos estudios exponen la importancia de la mujer cautiva en el mundo mapuche, desde el punto de vista simbólico, económico y cultural. Ver más en Socolow (1992) y Lázaro (1994)

15 Medina (1906: 409-410). En muchos casos cabe concluir que si bien muchos cautivos y cautivas comenzaban su paso "allende la frontera del Otro, el enemigo" desde la base de la desconfianza, algunos lograron ascender a roles de prestigio y confianza. En el caso 
Con el correr de los años, la intervención de elementos como los afectos, apegos y la asimilación al grupo captor, aunque sea en una posición desmejorada, promovía que la condición de cautivo se desdibujara y se encaminara hacia otras clasificaciones. En estos casos, su devolución y retorno podía hacerse indeseada de parte del captor y también del ahora ex cautivo. En relación a los rescates y truques de cautivas, Pedro Melendez señala en 1612 "...en cuanto a las mujeres españolas, de quienes tienen muchos hixos [los mapuches], que son su propia sangre, ni ellos ni ellas los querrán dezar" (Rosales, 1887:565). En parte ya no se trataba de un prisionero, sino de una madre, una esposa, una hija, la que solo en su origen como miembro del grupo contenía su condición de cautiverio. ${ }^{16} \mathrm{En}$ estas circunstancias se hacía imposible cederlo como pieza de intercambio, pues no había compensación para reemplazarlo. Conocido es el caso de la fuga de las esposas de Anganamón, entre las que se contaba una española cautiva. Para el cacique no hubo pago o compensación posible y la única alternativa ante tal desagravio era la devolución de sus mujeres. En vista de la negativa de parte de las autoridades hispanas, Anganamón organizó su ataque que terminó con el episodio del "martirio de Elicura". ${ }^{17}$ También podemos mencionar en este

de los mapuches, se promovía su bautismo. Para los cautivos españoles, muchos debían "abandonar su nombre y tomar otro indígena que simbolizara algunas cualidades militares". Otros prisioneros aportaron sus dotes para forjar el hierro, fabricar frenos, espuelas, puntas para las lanzas y otros instrumentos. Un caso emblemático es el protagonizado por Alonso Díaz, aquel mestizo que durante largos años combatió contra los españoles bajo los gobiernos de Quiroga, de Ruiz de Gamboa y de Sotomayor, era conocido entre los indios con el nombre de Paiñenancu o, más propiamente, Paiñancu, que significaba águila grande. La superioridad de su inteligencia, su conocimiento de las armas y de la táctica militar de los españoles, convertían pronto a estos auxiliares en jefes de los indios de guerra (Barros Arana, 1999: 117).

16 Para el problema de la liminalidad de la condición de cautivo revisar Sánchez, 2010.

17 La muerte de los misioneros jesuitas en manos del cacique Anganamón, conocido también como el "martirio de Elicura", se refiere al conflicto entre las autoridades indígenas e hispanas tras la huida de las tres esposas del cacique hacia el sector hispano en plenas negociaciones para acordar una tregua entre las partes. Dicho pacto, que no contaba con total apoyo de la elite criolla, demandante del comercio de esclavos generado al alero del conflicto, ni de todas las autoridades mapuches, recelosas de las buenas intenciones españolas, estaba en pleno proceso y sus alcances en la región dependían en gran medida del resultado de la paz con Anganamón. Así, mientras el cacique se aprestaba a concretar el acuerdo, para lo cual, como de costumbre, reunía prisioneros cautivos en su poder para su canje (como símbolo de buena fe), tres de sus esposas, una de ellas española cautiva, emprendieron su escape hacia el fuerte de Paicaví, junto con Juan Torres, sargento también cautivo de Anganamón. Este hecho que en sí mismo arriesgaba todo lo logrado en favor de la paz, fue agravado tras la negativa de las autoridades de devolver a sus mujeres. El 7 de diciembre llegaron al fuerte los caciques con sus tropas con 'ramos de canelo en las manos', a tratar las paces, solo bajo la condición de la demolición del fuerte y la entrega de las mujeres. Sin embargo, las mujeres ya bautizadas no podían entregarse. El fuerte sería demolido y los tres misioneros irían a parlamentar el conflicto de las mujeres con Anganamón. El hermano Diego de Montalbán, el padre Martín de Aranda y Horacio Vecchi iban con los caciques rumbo a Elicura, el día 9 de diciembre, esperando lograr el acuerdo a partir del pago de una compensación por las 
sentido el caso de Lientur, quien en 1617 atacó la zona de Chillán junto con el cacique Cayeguemo. Ambos habían combatido para las fuerzas hispanas pero cambiaron de bando después de que estos rescataran a una cautiva que tenía como concubina (Gay, 1845).

En otras ocasiones, son los mismos cautivos quienes no deseaban volver. Según explica Carlos Lázaro, es muy posible que para algunos ex cautivos las críticas y rechazo de la sociedad española ante los rumores de amancebamiento, herejía e incesto frenara, particularmente en el caso de las mujeres, el deseo del retorno. Fray Baltasar de Ovando, explica que "los desdichados españoles cautivos que aunque tienen ya libertad para salir del cautiverio, o ya por la vergüenza de parecer entre los suyos, olvidados de la policía, y nativa lengua, o lo que es más cierto por estar ya tan enviciados en las costumbres de los indios, que lo menos que tienen aprendido dellos es la poligamia" (Relación verdadera de las paces del Marqués de Baides, 1642, BNM: f.802r). En el caso de las cautivas españolas, la reinserción podía ser mucho más compleja dado que la mayoría de ellas habían tenido hijos con hombres mapuches, por lo que eran bastante despreciadas. Lázaro se afirma de los testimonios de Quiroga y González de Nájera para constatar que muchas mujeres ya sea por vergüenza o por amor a sus hijos mestizos deciden permanecer voluntariamente entre sus captores. ${ }^{18}$ No tenemos registros respecto a las dificultades del retorno para las mujeres mapuches cautivas.

Concluimos, entonces, que ante la dificultad de imponer una soberanía definitiva en la región a partir de la supremacía militar, ambos sectores, hispano y mapuche, se vieron en la obligación de recurrir a nuevos agentes y espacios de negociación con su oponente. Uno de los objetivos para buscar ese vínculo era concertar con éxito la entrega de los numerosos prisioneros que ya hacían perdidos durante décadas de conflicto.

Comenzando el siglo XVII, se planteó un giro en las políticas de contacto interétnico, las que dieron cabida a mayores espacios de interacción, ambigüedad y negociación, más allá del binomio guerra/paz. El paradigma de

mujeres. Pero el pago no se realizó al ser ambos asesinados. La confusión fue enorme y no solo murieron los sacerdotes y numerosos mapuches que los acompañaban, sino también parte de fe en los alcances del proyecto de la guerra defensiva. Algunos documentos que se refieren al tema son Sobrino (22 de marzo de 1635) y Vásquez (22 de marzo de 1635).

18 Carlos Lázaro cita a Quiroga (1979) y expone "iban los indios a traer a algunas cautivas, las cuales aunque se había, i concluido los conciertos de sus rescates no querían venir delante de los nuestros por verse preñadas, escogiendo por mejor partido el quedarse condenadas a perpetua esclavitud antes de padecer tal vergüenza ante los ojos de sus maridos y de todo el campo. Las que se resolvían, a volver al lado de los suyos traían los rostros tapados". Una parte de las mujeres optó por quedarse en territorio indígena porque movidas por su amor de madre y ante el posible escarnio público. Citado por Carlos Lázaro (1994: 202-203). 
una "guerra defensiva" comenzó a tomar fuerza, frente a la alternativa de "guerra total". En 1612 se aprobó a través de una Real Cédula el cambio de estrategia. Este nuevo modelo de acceso a la zona no ocupada, proponía principalmente el establecimiento de una frontera permanente, cuyo eje divisorio recaía en el río Bío-Bío y requería, al mismo tiempo, la interrupción de las incursiones bélicas a territorio indígena, el cese de la quema de viviendas y sembrados mapuches, así como la captura de prisioneros para su venta como esclavos. Al mismo tiempo, fijaba la presencia de misioneros para avanzar en el proceso de evangelización y rescate de cautivos.

Con el establecimiento de esta frontera se instaló desde el punto de vista sociocultural una mayor horizontalidad en las relaciones interétnicas. Ninguna de las partes se encontraba en posición de derrotar definitivamente a su adversario y no quedó más alternativa que la transacción. Era imposible demandar o imponer. Así, entonces, las relaciones interétnicas se fundaron fuertemente a partir de prácticas de violencia, pero también de mediación y diálogo. Las dinámicas expuestas promovieron el surgimiento y proliferación de nuevos agentes especializados en estos fines. En estos años se fue consolidando una plataforma común de signos y códigos reconocidos y aceptados por los distintos actores, que permitieron mediar en un lenguaje común acuerdos y pactos, los que al mismo tiempo fueron utilizados como instrumento para la liberación de cautivos. Este conjunto de reglas y métodos dictaban de alguna forma el "correcto proceder" para efectuar las parlas y convenios y fue el recurso del cual se valieron, tantos los redentores como los diversos agentes fronterizos, entre ellos los mismos prisioneros, para gestionar el rescate de personas.

Sin la presencia de estos mecanismos mínimos de comprensión e intersubjetividad, hubiese resultado imposible lograr la liberación de cautivos a través de la negociación y la interacción. El rescate hubiese quedado relegado exclusivamente a incursiones de guerra. Fue la diplomacia abierta y el desarrollo de las relaciones interétnicas durante este periodo las que dieron cabida a instancias alternativas redención de cautivos, españoles y mapuches aliados y autónomos o "rebeldes".

\section{Referencias bibliográficas}

\section{Fuentes secundarias}

Archivo Arzobispado de Santiago (1613). Información que se hizo con los que estuvieron presos sobre lo que dijeron al Padre Luis de Valdivia de la Compañía de Jesús, acerca de la guerra de Chile, Fondo Gobierno, Vol. 52, Documentos diversos (1599-1655), 31 de marzo, ff. 231-238. 
Archivo del Arzobispado de Santiago (1611). Memorial del padre Luis de Valdivia de la Compañía de Jesús sobre hacer la guerra defensiva a los indios. Fondo Gobierno. Vol. 51, Documentos diversos (1577-1613), ff. 363-410.

Biblioteca Nacional (17 de mayo de 1619). José Toribio Medina, Rollo MS, M.71 (FJ. 97 - 99), f. 97.

de Medina, D. (12 de abril de 1615). Declaración de Diego de Medina que estuvo cautivo entre los indios sobre el estado de aquellas cosas. Archivo Arzobispado de Santiago, Fondo Gobierno Vol. 80, Guerra de Chile -1660-1620-, ff. 243-247.

de Valdivia, L. (1611). Documentos Diversos (1577-1613). Archivo del Arzobispado de Santiago. Memorial del padre Luis de Valdivia de la Compañía de Jesús sobre hacer la guerra defensiva a los indios. №38, segundo orden, ff. 363-410.

de Valdivia, L. (1621). Biblioteca Nacional. Diego Barros Arana. Rollo MS. BA.4 (fj.1-16). Tomo 11, f. 1.

del Salto, L. \& García Ramón, A. (1606). El governador. 15 de agosto. En una relación de las personas que se han rescatado del poder del enemigo, Concepción: Alonso García Ramón, gobernador Chile: estado de la guerra (1). Concepción 15 de agosto de 1606. Archivo General de Indias, Patronato 228, R.57. s/f.

Falcón, J. (abril 1614). Gobierno y estado de la guerra de Chile. Archivo General de Indias, PATRONATO, 229, R. 40.

García de Ramón, A. (30 de diciembre de 1605). Alonso García Ramón, gobernador Chile: estado de la guerra, Concepción, 30 de diciembre de 1605. Archivo General de Indias, Patronato 228, R.57, f.6-6v.

García Ramón, A. (1604). Estado y Socorro de Chile: Acta del acuerdo de una junta de guerra celebrada en Santiago de Chile en 18 de junio de 1604, sobre recursos para la campaña de Arauco. XII. 96. [Tomo VII], Archivo General de Indias, Patronato 228, R.45, s/f, imagen 516-517.

García Ramón, A. (1606a). Alonso García Ramón, gobernador Chile: estado de la guerra, Concepción, 15 de agosto de 1606. Archivo General de Indias, Patronato, 228, R.57, s/f.

García Ramón, A. (1606b). El governador 15 de Agosto. En una relacion de las personas que se han resgatado del poder del enemigo. Archivo General de Indias AGI. Patronato 228, R.57, s/f, Alonso García Ramón, gobernador Chile: estado de la guerra.

García Ramón, A. (1606c). Relación de la guerra que el gobernador Alonso García Ramón hizo este verano de 1606 a los indios enemigos. Archivo Arzobispado de Santiago, Fondo de Gobierno, Vol. 53, Documentos diversos, 1605-1610. 
Laso de la Vega, F. (1633). Carta del gobernador Francisco Laso de la Vega sobre la solicitud del fiscal de la Real Audiencia de Chile para que se pague el quinto real por los indios, ganado y caballos capturados en la guerra. Archivo General de Indias. Audiencia de Chile 20, Cartas de Gobernadores, R.1, N.49 s/f, 15 de abril.

Reino de Chile y Colegio de Santiago (1577-1613). Estado de las misiones de Chile i defensa de los misioneros de la Compañía de Jesús. Cap $8^{\circ}$ De cómo segunda vez se volvió a determinar la entrada de los padres de la Compañía a los indios de guerra i las circunstancias que en ello hubo. Archivo Arzobispado de Santiago, Fondo Gobierno, Vol. 51, Documentos diversos, ff. 215-316.

Reino de Chile y Colegio de Santiago (1577-1613a). Estado de las misiones de Chile i defensa de los misioneros de la Compañía de Jesús. Cap. 10 De algunas circunstancias que hacen gloriosa la muerte de estos benditos padres i sus virtudes. Archivo del Arzobispado de Santiago, Fondo Gobierno. Vol. 51, Documentos diversos, -1577-1613-, ff. 215-316.

Relación (1642). Relación verdadera de las paces del Marqués de Baides... BNM: f.802r, manuscrito, 2372.

Sobrino, G. (22 de marzo de 1635). Padre Gaspar Sobrino: medios para remediar la guerra de Chile. Archivo General de Indias, Patronato 229, R. 26. Cartas Annuas, Chile. 6.

Sobrino, G. (s/f, a). El Padre Gaspar Sobrino de la Compañía de Jesús a quien el Padre Luis de Valdivia ha embiado del Reyno de Chile propone a V.Magestad algunas razones, que pruevan la eficacia de los medios resultos cerca los negocios del dicho Reyno.

Sobrino, G. (s/f, b). Medios para remediar la guerra de Chile. Archivo General de Indias, Patronato 229, R. 26, 1-12v, s/f.

Vásquez, R. (22 de marzo de 1635). Cartas Annuas. Archivo General de Indias, Patronato 229, R. 26, Chile. 6.

\section{Fuentes secundarias}

BARROS ARANA, D. (1999). Historia General de Chile. Tomo III. Santiago de Chile: Editorial Universitaria: Centro de Investigaciones Diego Barros Arana.

CABRERA, E. (1996). "De nuevo sobre cautivos cristianos en el Reino de Granada", en Meridies, Revista de Historia Medieval, 3.Universidad de Córdoba, Facultad de Filosofía y Letras, Área de Historia Medieval, p. 137-160.

DE OVALLE, A. (1969). Histórica Relación del Reyno de Chile. Santiago de Chile: Instituto de Literatura Chilena, Editorial Universitaria. 
GAY, C. (1845). Historia física y política de Chile: según documentos adquiridos en esta república durante doce años de residencia en ella y publicada bajo los auspicios del Supremo Gobierno.Parte 1, Volumen II. París: 8 vols., 1 Atlas. Editorial Faine \& Thunot.

GONZÁLEZ, J. (2001-2002). "El cautiverio femenino y mestizaje al revés en la Araucanía del siglo XVII. La conquista de la mujer del otro", en Educación y Humanidades, 10-11. Talca: Instituto de Investigación y Desarrollo Educacional, Universidad de Talca, p. 72-95.

GUARDA G. (1987). "Los cautivos en la guerra de Arauco", en Boletín de la Academia Chilena de la Historia, 98. Santiago, p. 101-102.

GUARDA, G. (1990). Flandes indiano: las fortificaciones del Reino de Chile, 1541 1826. Santiago de Chile: Universidad Católica de Chile.

GUARDA, G. (1993). La nueva Historia de Valdivia. Santiago de Chile: Universidad Católica de Chile.

LÁZARO, C. (1994). "Los cautivos en la frontera araucana", en Revista Española de Antropología Americana, 24. Madrid: Complutense, p. 191-207.

MEDINA, J. T. (1906). Diccionario biográfico colonial de Chile. Santiago: Elziviriana.

OPERÉ, F. (2001). Historia de la Frontera: el cautiverio en la América Hispana. Buenos Aires: Fondo de Cultura Económica.

QUIROGA, J. (1979). Memoria de los sucesos de la Guerra de Chile. Santiago: Editorial Andrés Bello, Santiago.

SÁNCHEZ, M. (2010). "Los cautivos en el Chile colonial: problemas en la clasificación de un 'tipo ideal'", en Alejandra Araya y Jaime Valenzuela (Eds.). América Colonial. Denominaciones, clasificaciones e identidades. Santiago de Chile: RIL, p. 219-235.

SOCOLOW, S. (1992). "Spanish captives in Indian Societies: Cultural contact along the Argentine frontier, 1600-1835", en Hispanic American Historical Review, 72, I. Duke: Duke University Press, p. 73-99.

SESMA, A. (2002). "Guerra, Ejército y Sociedad en los Reinos de Aragón y Navarra en la Edad Media", en Revista de Historia Militar, Año XLVI, p. 13-48.

SUELDO, M. y GREBLIAUSKIENE, B. (2011). "Esbozos del protocolo diplomático y su desarrollo en el tiempo bajo el prisma de la comunicación', en Papeles de Trabajo - Centro de Estudios Interdisciplinarios en Etnolingüística y Antropología Socio-Cultural, 21, p. 62-79.

URBINA, X. (2009). La frontera de arriba en el Chile colonial. Valparaíso: Pontificia Universidad Católica de Valparaíso, Centro de Investigaciones Diego Barros Arana. 
ZAVALA, S. (1998). "L'envers de la «Frontière» du royaume du Chili. Le cas des traités de paix hispano-mapuches du XVIII e siècle", en Histoire et sociétés de I'Amérique latine, 7. Association Aleph, IHEAL, Universités Paris 7, Paris 1, p. $185-208$. 